\title{
EVALUACIÓN DEL DAÑO EN EL ADN EN DOS POBLACIONES COLOMBIANAS DE AGRICULTORES Y FLORICULTORES
}

\section{ASSESMENT OF DNA DAMAGE IN TWO COLOMBIAN POPULATIONS OF AGRICULTIRIST AND FLORICULTURIST}

\section{RESUMEN}

Algunas investigaciones demuestran el potencial genotóxico de ciertos plaguicidas sobre los seres humanos, lo cual, hace necesario el desarrollo de metodologías que permitan evaluar el impacto de dichas sustancias, para alterar el ADN. El ensayo del cometa alcalino es un método económico, rápido y sensible que detecta, principalmente, rompimientos de cadena sencilla y sitios lábiles al-álcali en células individuales. El objetivo del presente estudio fue evaluar el daño en el ADN, en una población de floricultores y agricultores ocupacionalmente en contacto con plaguicidas y compararlo con un grupo control. Se obtuvieron muestras de sangre periférica de 101 personas, entre trabajadores expuestos e individuos del grupo control. El ensayo del cometa, se realizó utilizando sangre total y linfocitos aislados, con muestras embebidas en agarosa y puestas sobre una lámina portaobjetos; luego expuestas a una solución de lisis con detergente y, posteriormente, sometidas a una corriente eléctrica, con buffer alcalino. El daño en el ADN fue evaluado por medición del largo de la cola (migración de ADN) y por la morfología que presentaban los cometas. En los agricultores, el ensayo mostró un incremento significativo $(p<0,001)$ del daño

${ }^{1}$ Biólogo y Químico, Magister en Biología con énfasis en Genética Humana. Dirección para correspondencia: Laboratorio de Biología Molecular. Universidad de Ciencias Aplicadas y Ambientales U.D.C.A. Bogotá, Colombia. Calle 222 No $^{\circ} 54-37$. Telefono 6684700 ext 154. Correo electrónico: andremunoz@udca.edu.co en el ADN, comparado con los floricultores y el grupo control; entre estos últimos, no se hallaron diferencias. Los resultados sugieren que el ensayo de cometa puede ser un buen biomarcador de exposición ocupacional a plaguicidas y que puede ser utilizado para este tipo de estudios.

Palabras clave: Genotoxicidad, ensayo del Cometa, plaguicidas, exposición ocupacional.

\section{SUMMARY}

Some research results prove the potential genotoxic activity of pesticides on human beings, which makes the development of methodologies that allow the determination of capacity of these substances to damage the DNA necessary. The comet assay is an economic, rapid and sensitive method that allows to detect, mainly, single strand breaks and alkaly-labil sites in individual cells. The aim of the present study was to evaluate the DNA damage by means of the comet assay in populations engaged in floriculture and agriculture activities, with variable exposure to pesticides, compared with a control group. Peripheral blood samples from a total of 101 individuals were obtained. The comet assay was performed using total peripheral blood as well as isolated lymphocytes. For this procedure the samples were embedded in agarose and set on a microscope slide, exposed to a lyses solution with detergent and finally to electrophoresis with alkaline buffer. Measuring the length of the comet tail (DNA migration) and the morphology of the comets, the DNA damage was estimated. In the exposed farmers, the comet assay revealed a statistically 
significant increase in DNA damage $(\mathrm{P}<0.001)$ versus floriculturists and the control group, but no difference between these later two groups were observed. The results suggest that the comet assay could be a reliable biomarker for occupational exposure to pesticides and that it could also be useful for similar studies.

Key words: Genotoxicity, Comet assay, pesticides, occupational exposure.

\section{INTRODUCCIÓN}

Los plaguicidas han sido un aliado, sobre todo para los países en vías de desarrollo, en sus esfuerzos a erradicar enfermedades endémicas llevadas por insectos, producir alimentos y proteger bosques; sin embargo, algunos son una fuente de riesgo potencial al ambiente y organismos, que no son su objetivo. Son varios los estudios que relacionan la exposición a ciertos plaguicidas solos y en mezclas (organofosforados, clordano, dieldrin, aldrin dicamba, atrazina y lindano, entre otros) con un riesgo aumentado a linfomas No-Hodgkin, leucemia y mieloma múltiple (Orsi et al. 2007; Merhi et al. 2007; Mester et al. 2006; De Roos et al. 2003); sin embargo, estudios epidemiológicos sobre el riesgo de cáncer en agricultores generan resultados confusos (Viel et al. 1998; Blair et al. 1998); de ahí, los efectos indeseables sobre la salud, causados por ciertos plaguicidas en la población son de interés especial. Entre estos son sus efectos como genotoxicos, incluyendo el cáncer y varias otras enfermedades genéticas (IARC, 1991; Lebailly et al. 1998). El biomonitoreo de poblaciones expuestas a potenciales cancerígenos es un sistema temprano de advertencia para enfermedades genéticas o cáncer, lo que permite identificar factores de riesgo $\mathrm{y}$, a la vez, adaptar medidas de control (Kassie et al. 2000). Muchas técnicas son desarrolladas para vigilar las poblaciones humanas, expuestas a genotóxicos ambientales; por ejemplo el biomonitoreo en humanos puede ser realizado usando diferentes marcadores genéticos; los marcadores citogenéticas, como aberraciones cromosómicas (CA), micronúcleos (MN) y el intercambio de cromátides hermana (ICHs) están entre los más ampliamente usados, para evaluar los efectos genotóxicos de los plaguicidas. Varias investigaciones aplican pruebas citogenéticas para evaluar el potencial genotóxico de la exposición ocupacional a plaguicidas en poblaciones expuestas de varios países (Davies et al. 1998; Blasiak et al. 1999; Gómez-Arroyo et al.
2000; Zeljezic E Garaj-Vrhovac, 2001) y en diferentes reportes de efectos genotóxicos positivos en poblaciones expuestas a plaguicidas (Garaj-Vrhovac \& Zeljezic, 1999; Antonucci \& Colus, 2000; Álvarez et al. 2001; Tisch et al. 2002; Rahman et al. 2002; Varona et al. 2003), así como negativos (Lucero et al. 2000; Pastor et al. 2001a,b). Este conflicto en los resultados de los biomonitoreos de plaguicidas prueba la heterogeneidad de la exposición (e.g. agricultores, floricultores y trabajadores en la manufactura de plaguicidas), los diferentes usos de los plaguicidas y las medidas de protección.

Durante los últimos años, el ensayo del cometa, también llamado Electroforesis Alcalina en Células Individuales (EACI), incrementó su uso en estudios de biomonitoreo humano. Esta técnica descrita en primera instancia por Ostling $E$ Johanson (1984) y modificado por Singh et al. (1988) y Olive et al. (1988) es una técnica sensible, eficiente y fácil de hacer, permitiendo observar el daño en el ADN de forma individual. Este daño producido obedece a diferentes tipos de interacción con los ácidos nucleicos, lo cual, puede generar rupturas de cadena sencilla, rupturas de cadena doble, entrecruzamientos y sitios lábiles al álcali. La metodología permite evidenciar el efecto total de una o varias sustancias genotóxicas sobre el ADN, no discrimina en el efecto que puede tener cada una de ellas ante la exposición, pero sí permite evaluar todo tipo de daño estructural en la hebra de ADN, convirtiéndose en un excelente biomarcador de exposición. La técnica, se basa en la fijación de células en un gel de agarosa, exponerlas a detergentes que disuelvan la membrana citoplasmática y limpiar residuos de organelos, de esta manera, se obtienen núcleos desnudos que se sumergen en un buffer alcalino, que permite desenrollar el ADN, posteriormente someter estos núcleos a una corriente eléctrica, así los daños estructurales en la hebra de ADN generan pequeños fragmentos que migran desde el interior del núcleo al exterior; la cantidad de rompimientos en el ADN en las células se ve reflejado en la formación de cola de migración y este daño en el ADN es directamente proporcional a la longitud de la cola o la cantidad de fragmentos que se encuentren fuera del núcleo (Anderson et al. 1994, Rojas et al. 1999, McKelvey $\mathcal{E}$ Valerie, 1998). En el presente trabajo el ensayo del cometa fue usado para evaluar el daño en el ADN de agricultores y floricultores ocupacionalmente expuestos a diferentes clases de plaguicidas en su lugar de trabajo y compararlo con un grupo control. 


\section{MATERIALES Y MÉTODOS}

Sujetos: El ensayo del cometa fue realizado en 101 muestras de sangre periférica pertenecientes a agricultores, floricultores y un grupo control. El grupo de agricultores de papa y de cebolla de bulbo fue constituida por 33 trabajadores que laboraban en ambos cultivos, realizando actividades de siembra, cosecha y aplicación de plaguicidas, entre las más importantes. Esta población estuvo formada por 18 hombres y 15 mujeres, con promedios de edad de 28,1 años y 34,4 años, respectivamente; quienes tienen una media de 15,1 años dedicados a esta actividad; estos son cultivos abiertos y se encuentran ubicadas en las veredas de Páramo Centro, Patagui, Tibaquirá y Valle, en el municipio de Samacá (Boyacá), en el centro de Colombia. La población de floricultores fue constituida por 35 trabajadores, 18 hombres y 17 mujeres, con promedios de edad de 32,4 y 35 años, respectivamente; empleados en diferentes secciones de dos empresas floricultoras, en la que se produce alstroemeria y pompón, y presentan una media de 7,6 años trabajando en estas empresas. Los cultivos se encuentran en el municipio de Madrid (Cundinamarca) y el proceso de cultivo se realiza bajo cubierta; las principales actividades de estos trabajadores son el cuidado de los cultivos, la aplicación de plaguicidas y el empaque de flores. El grupo control estuvo compuesto por 33 personas, 15 mujeres y 18 hombres, residentes en las poblaciones donde se encuentran ubicados los cultivos, quienes no presentaban ninguna exposición ocupacional a plaguicidas, además no tenían antecedentes de exposición a plaguicidas o a agentes químicos o físicos que pudiesen ser tóxicos para los humanos. Las condiciones socioeconómicas de las poblaciones fueron similares. Cada una de las personas participantes del estudio en el momento de la toma de la sangre firmaron un consentimiento informado, en el cual, se les daba a conocer los objetivos del estudio y permitían el uso de su sangre con fines investigativos; así mismo, se tomó un cuadro hemático y se evaluó el nivel de acetil colina esterasa. Se excluyeron del estudio personas que se encontraban ingiriendo alguna clase de medicamentos o habían sido expuestos a algún tipo de radiación (terapéutica o diagnóstica) en los últimos doce meses antes de la toma de sangre. El estado de salud de todas las personas participantes fue evaluado a través de un examen médico; todos, en general, presentaban buena condición física. Los plaguicidas utilizados, los detalles de la historia clínica, los datos personales y la información sobre el consumo de alcohol y cigarrillo fueron obtenidos por medio de la aplicación de un cuestionario estándar, por parte de personal entrenado.

Ensayo del cometa: La muestra de sangre fue tomada en Vacutainer ${ }^{\circledR}$ con Heparina y consecutivamente fue almacenada en hielo y llevada al laboratorio. El ensayo del cometa fue realizado en condiciones alcalinas de $\mathrm{pH}$, de acuerdo a Tice (2000); para tal fin, sobre una lámina portaobjeto con una capa delgada de agarosa de punto de fusión normal, $1 \%$ se depositó una mezcla de $10 \mu \mathrm{L}$ de muestra suspendida en $90 \mu \mathrm{L}$ de agarosa de punto de fusión bajo 0,5\%, después de polimerizar, se adicionó una nueva capa de $100 \mu \mathrm{L}$ agarosa de punto de fusión bajo 0,5\%; durante la polimerización del gel, una lámina cubreobjeto, se colocó para obtener una capa delgada y uniforme; de cada individuo, se realizaron tres réplicas. Posteriormente, las láminas fueron inmersas en solución de lisis ( $\mathrm{NaCl} 2,5 \mathrm{M}$, EDTA 100mM, Tris- $\mathrm{HCl} 10 \mathrm{mM}$, Lauryl sarcosinato de sodio $1 \%$, Tritón $1 \%$ y DMSO 10\%), a $4^{\circ} \mathrm{C}$. Después de dos horas, las láminas fueron puestas en reposo alcalino en buffer de electroforesis $(\mathrm{NaOH}$ $10 \mathrm{~N}$ y EDTA $200 \mathrm{mM}$, pH 13,1), por 30 minutos. Luego del reposo alcalino, la electroforesis es realizada en una cámara de electroforesis horizontal, a baja temperatura, por 30 minutos y $300 \mathrm{~mA}$. Las láminas fueron sacadas y lavadas con solución neutralizante (Tris- $\mathrm{HCl} \mathrm{pH} \mathrm{7,5),} \mathrm{por}$ 15 minutos. Para la lectura de las láminas, se colorearon con bromuro de etidio $10 \%$ y se observaron en un microscopio de fluorescencia Zeiss, equipado con un filtro excitador de 515-560nm. Para cada lámina fueron analizadas 50 células, determinando el largo de la cola del cometa (Tice, 2000), midiendo desde el centro del núcleo hasta el punto más alejado de la cola del cometa, este valor se da en micras (Fotografía 1). También, se realizaron mediciones de la morfología del núcleo (Anderson et al. 1994), que los clasifica por el nivel de daño que presenta el cometa, así: ninguno (0-5\% de daño en el ADN), bajo (5-10\%), medio (10-40\%), alto (40-95\%) y total (95-100\%) (Fotografía 2). Los reactivos utilizados fueron obtenidos de los laboratorios Sigma, Analyticlas, Gibco y Merk.

Análisis Estadístico: Para analizar las posibles diferencias entre el largo de la cola del cometa entre las poblaciones estudiadas y la relación con otras variables, como la edad, los implementos de protección, el tiempo de exposición y el género, se utilizaron las pruebas estadísticas de $\mathrm{t}$ student, test pareado de Wilcoxon y Kruskal Wallis con el programa estadístico STATISTIX 7.0 ${ }^{\circledR}$. 


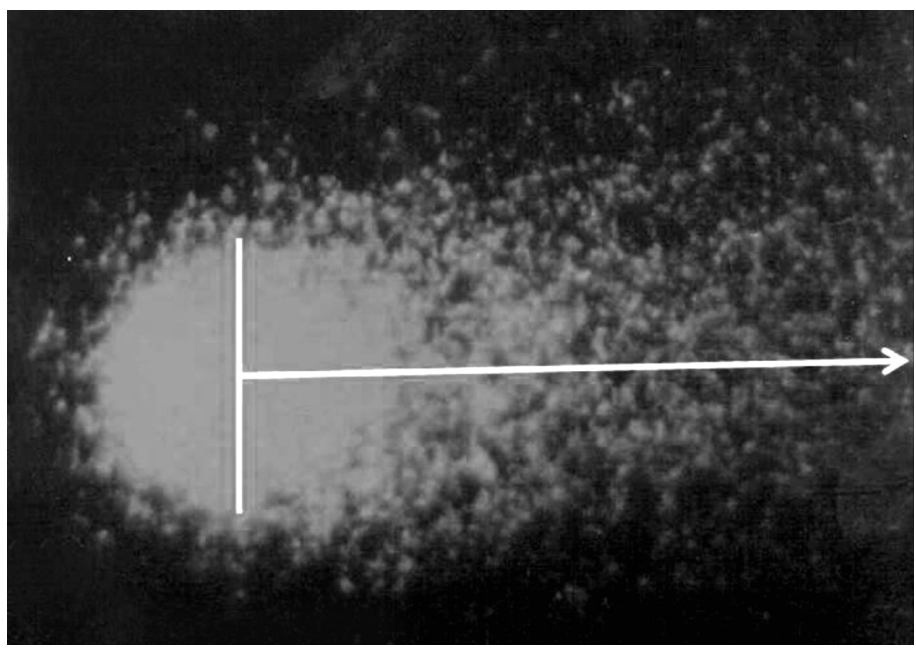

Fotografía 1. Medición del largo de la cola del cometa, medido en micras.

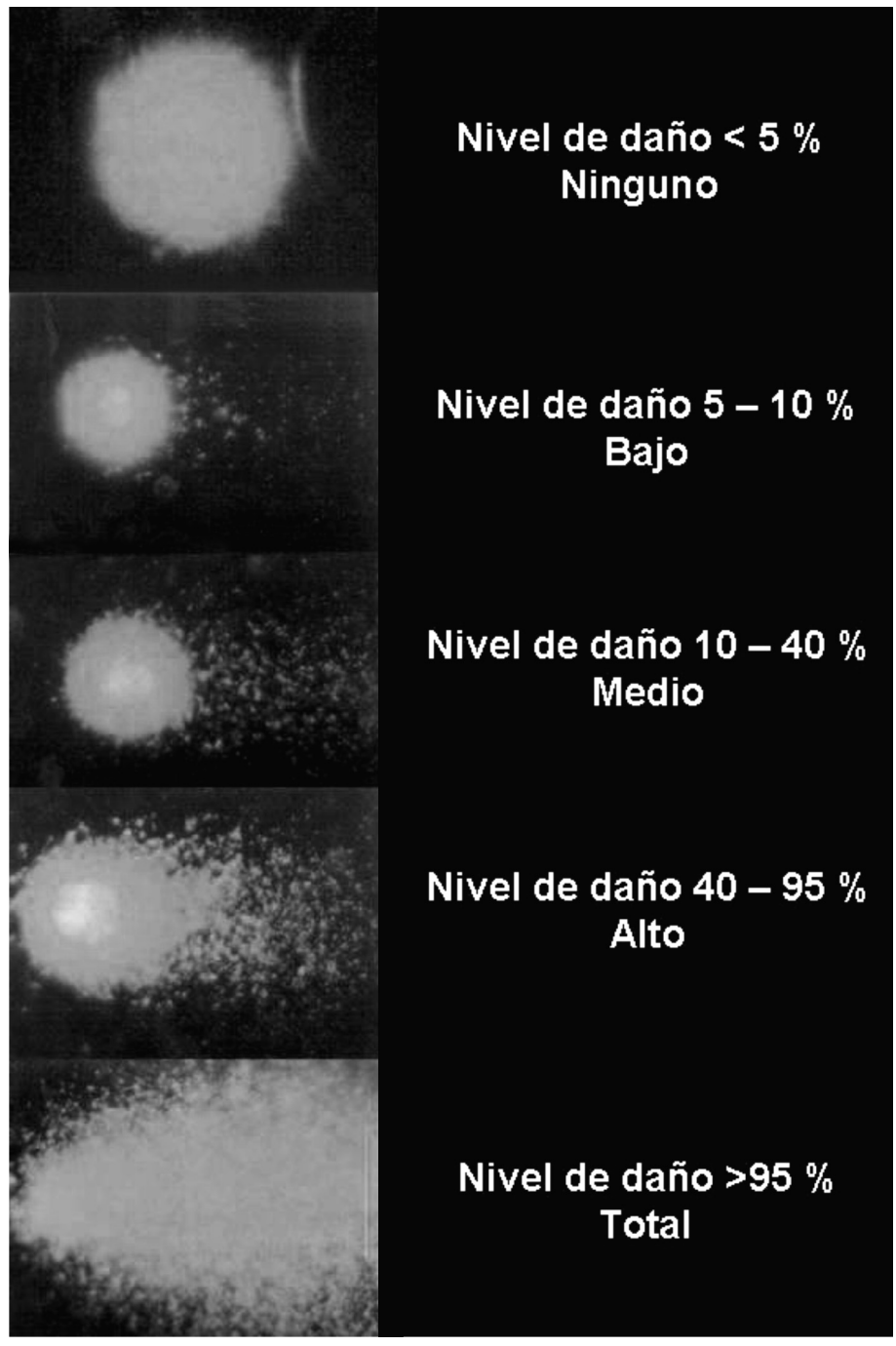

Fotografía 2. Clasificación de la morfología de los núcleos, según el nivel de daño en el ADN. 


\section{RESULTADOS Y DISCUSIÓN}

El examen médico realizado a cada una de las personas participante en el estudio mostró que ninguno padecía de problemas de salud, como desórdenes digestivos y respiratorios; adicionalmente, los resultados de la evaluación del nivel de acetil colina esterasa y el cuadro hemático estuvo dentro de los valores normales. La revisión de las encuestas aplicadas arrojó datos importantes sobre las condiciones de cada grupo de estudio; en la gráfica 1a, se presenta el porcentaje de uso de los plaguicidas por categoría toxicológica en los cultivos de papa y de cebolla. En Colombia, las cuatro categorías establecidas son: categoría IA: extremadamente tóxico; categoría IB: altamente tóxico; categoría II: medianamente tóxico y categoría III: ligeramente tóxico según Manual Técnico Andino y el Ministerio de Salud; cabe resaltar el uso frecuente y en altas dosis de plaguicidas catalogados altamente y moderadamente tóxicos; entre las clases de sustancias más utilizadas, se destacan los organofosforados $(16,22 \%)$, carbamatos $(6,76 \%)$ y de piretroides $(6,76 \%)$. De la información recolectada sobre los elementos de protección personal que utilizaban en el momento de la aplicación de plaguicidas, como botas, guantes, overol, delantal, gafas y mascarilla entre los más

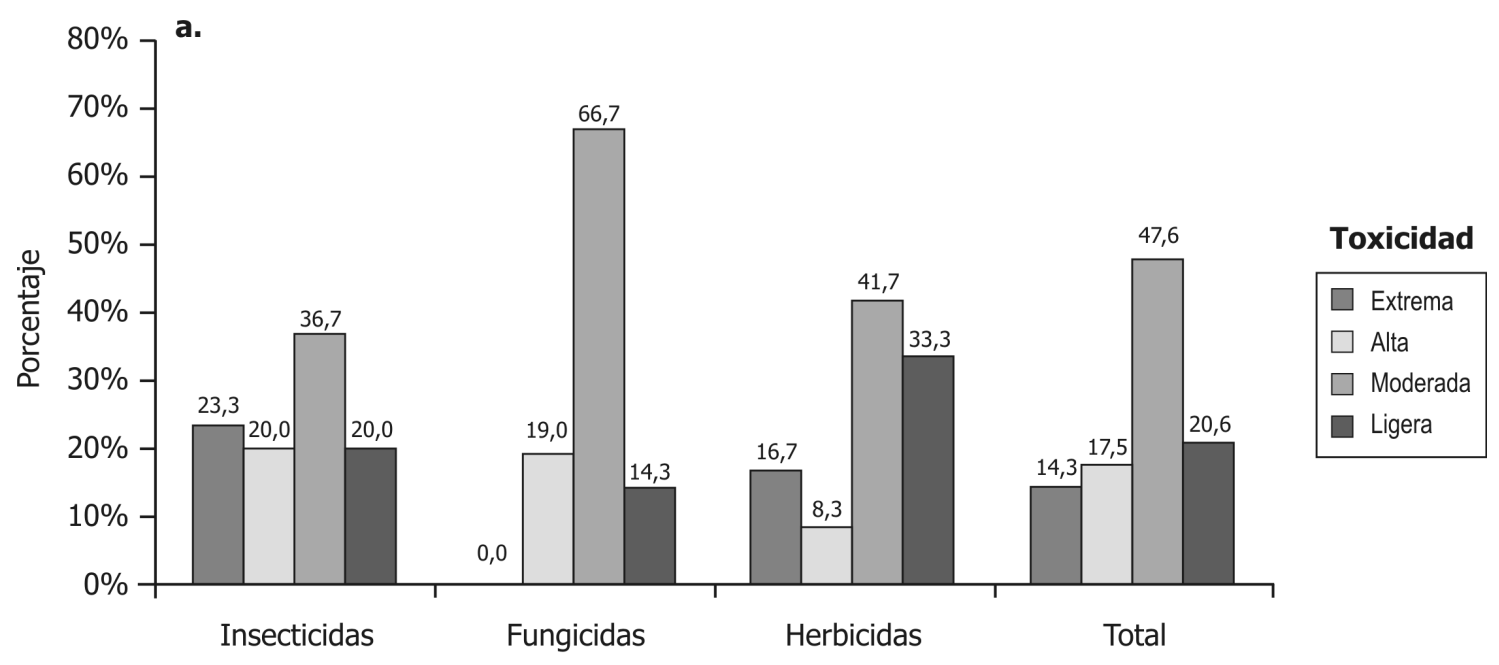

b.

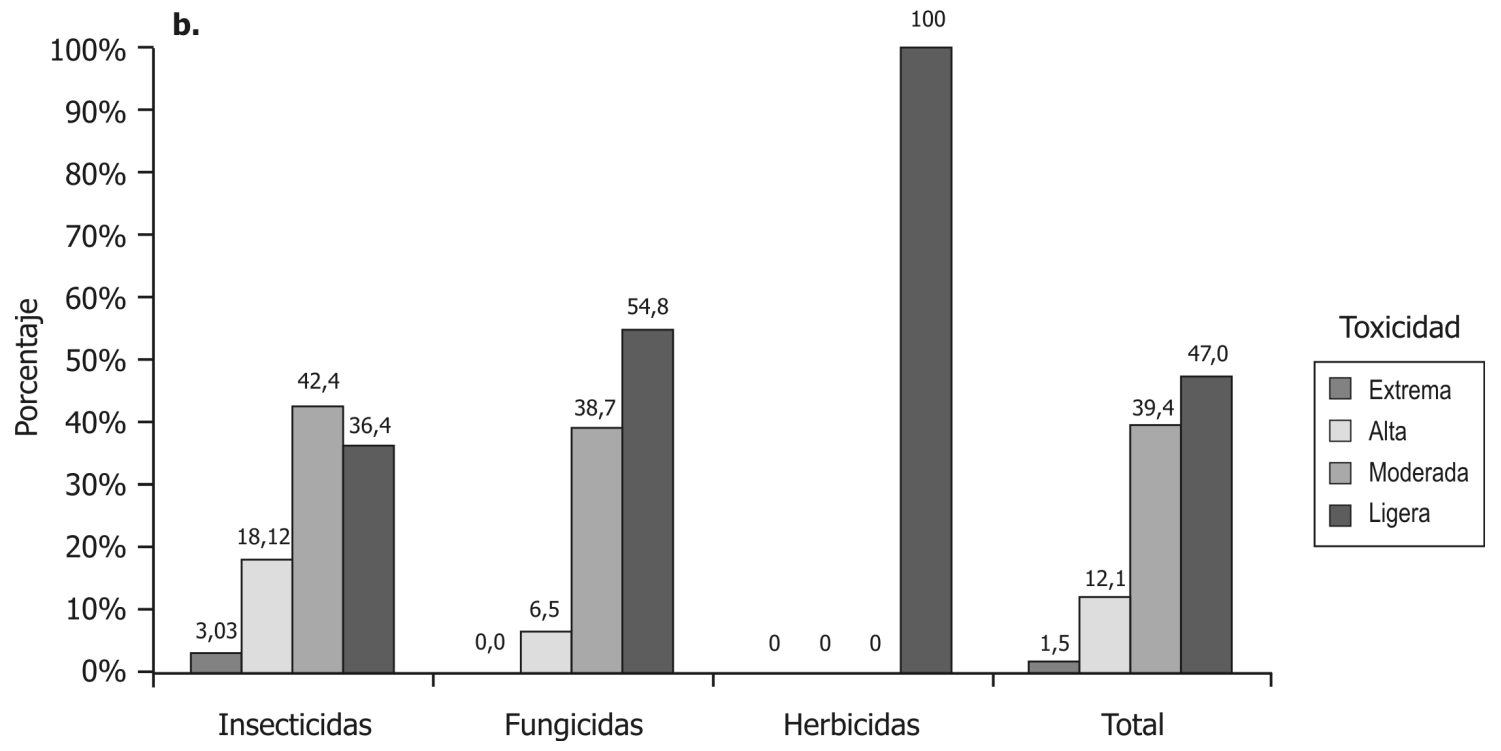

Gráfica 1. Distribución de los plaguicidas utilizados con respecto a su categoría toxicológica en (a) cultivos de papa y cebolla y (b) cultivos de flores. 
importantes, el $85 \%$ de los individuos carecían de cuatro o más elementos de protección al momento de las fumigaciones y el conocimiento de normas de seguridad para el uso de plaguicidas era muy bajo. En los cultivos de flores, el uso de plaguicidas, de categoría moderada y ligeramente tóxica, son los más utilizados, 39,4\% y 47,0\%, respectivamente (Gráfica 1b); el uso de organofosforados, carbamatos y piretroides no supera el $10 \%$, de acuerdo con lo encontrado por Varona et al. (2005). Se observó en esta población un correcto y frecuente uso de elementos de seguridad, pues el $100 \%$ de los floricultores utilizaban todos sus elementos de seguridad durante la aplicación de plaguicidas, así como un buen conocimiento y acatamiento de las normas de seguridad para el manejo y aplicación de plaguicidas y el respeto por los periodos de reentrada; es importante resaltar que los programas implementados en estos cultivos de flores sobre el manejo y el control de plagas minimiza el riesgo y el uso de plaguicidas altamente tóxicos.

La prueba del ensayo del cometa se pudo realizar en todos los sujetos del estudio; en las fotografías 1 y 2 se presentan algunos cometas obtenidos en las diferentes poblaciones de estudio. Respecto a los resultados, los agricultores mostraron una longitud media de la cola de los cometas de \pm D.E 62,32 $\pm 5,86 \mu \mathrm{m}$; la población floricultores una media de \pm D.E 25,61 $\pm 3,1 \mu \mathrm{m}$ y el grupo control presentó una de \pm D.E 23,46 $\pm 4,15 \mu \mathrm{m}$; estos resultados se presentan resumidos en la tabla 1. Se evidenció un incremento significativo en los valores del largo de la cola de los cometas analizados en la población de agricultores, respecto a las poblaciones de floricultores y el grupo control ( $p<0.001$ ), resultados también observados en trabajos anteriores de GarajVrhovac E Zeljezic. (1999, 2000, 2001 y 2002), Moller et al. (2000), Elhajouji (2001) y Moretti et al. (2002). Estos resultados se deben a que en la población de agricultores, la exposición ocupacional a plaguicidas en el cultivo es alta, ya que fue evidente la falta de implementos adecuados para su protección y el poco acatamiento de las medidas básicas de seguridad para el manejo de plaguicidas. Estos hallazgos, se pueden sustentar con los trabajos de Fairbairn et al. (1995) y Shah et al. (1997), quienes demostraron que algunos plaguicidas pueden inducir diferentes tipos de daño en el ADN y pueden ser detectados por el ensayo del cometa; así mismo, otros autores demostraron un efecto genotóxico de varios plaguicidas, a través de la misma prueba (Clements et al. 1997, Zeljezic E Garaj - Vrhovac, 2001). Entre la población de floricultores y el grupo control no se encontraron diferencias significativas ( $p$ $=0,074)$ y los resultados muestran en general un nivel de daño en el ADN bajo, lo cual es atribuible al uso adecuado de implementos de protección, el acatamiento de las normas de seguridad y el uso de plaguicidas moderada y ligeramente tóxicos en los cultivos de flores; cabe resaltar que el pequeño aumento de los resultados en el grupo de floricultores puede estar relacionado con cierta exposición a sustancias tóxicas y que debe ser tomada en cuenta en futuros estudios. Los resultados de la morfología de los núcleos presentan igual tendencia que los obtenidos con la longitud de la cola del cometa; el resumen de estos resultados se presentan en la tabla 1.

Tabla 1. Valor promedio y desviación estándar de la longitud del cometa, medido en micras $(\mu \mathrm{m})$ y morfología del núcleo en los sujetos de las población en estudio.

\begin{tabular}{|c|c|c|c|c|c|c|}
\hline \multirow{2}{*}{ Población } & \multirow{2}{*}{ Largo de la cola } & \multicolumn{5}{|c|}{ Porcentaje de núcleos en cada nivel de daño } \\
\cline { 3 - 7 } & & Ninguno & Bajo $^{2}$ & Medio $^{3}$ & Alto $^{4}$ & Total $^{5}$ \\
\hline Agricultores & $62,32^{* *} \pm 5,9$ & $0,94 \pm 5.4$ & $2,11 \pm 9,4$ & $16,38 \pm 9,6$ & $80,46 \pm 17$ & $0,10 \pm 0,3$ \\
\hline Floricultores & $25,61 \mathrm{NS} \pm 3,1$ & $7,17 \pm 2,1$ & $25,37 \pm 1,9$ & $61,37 \pm 1,9$ & $6,09 \pm 1,2$ & $0 \pm 0$ \\
\hline Grupo Control & $23,46 \mathrm{NS} \pm 4,2$ & $18,03 \pm 9,9$ & $56,74 \pm 7,8$ & $22,19 \pm 13,9$ & $3,05 \pm 2$ & $0 \pm 0$ \\
\hline
\end{tabular}

Grado de daño. ${ }^{1}$ Ninguno $<5 \%,{ }^{2}$ Bajo 5-10\%, ${ }^{3}$ Medio 10-40\%, ${ }^{4}$ Alto 40-95\% y ${ }^{5}$ Total $>95 \%$. ** $=$ Diferencias estadísticamente significativas $(p<0,001)$ con respecto a las demás poblaciones. NS $=$ No presentan diferencias significativas $(p>0,074)$. 
Cabe resaltar que el $80,46 \%$ de los núcleos de los agricultores presentó un nivel de daño alto, contrastando con los floricultores y grupo control, en quienes se observó niveles de daño medio $(61,37 \%)$ y bajo (56,74\%), respectivamente. Es importante resaltar la diferencia entre los resultados de los floricultores y el grupo control, pues al utilizar este parámetro de medición, se muestra una diferencia más marcada, aunque no es altamente significativa, su aumento es evidencia de exposición constante, que debe ser analizado más cuidadosamente con otras herramientas más específicas. En este estudio no se encontraron diferencias significativas cuando fueron comparados los resultados del ensayo del cometa entre hombres y mujeres en cada población ( $p>0,05)$, de acuerdo con lo publicado por Gómez et al. (1992). No se tiene evidencia que exista diferencia a nivel metabólico o de dinámica de reparación de ácidos nucleícos entre géneros, además las condiciones en cada población para ambos géneros son similares y las diferentes actividades que se realizan al interior de los cultivos son ejecutadas independientemente del sexo. Sin embargo, respecto a otras técnicas citogenéticas, como micronúcleos y aberraciones cromosómicas, algunos estudios han reportado diferencias significativas, entre hombres y mujeres expuestos y no expuestos a plaguicidas (Carbonell et al. 1990). Los resultados en este estudio no detectaron efecto alguno de la edad sobre los niveles de daño en el ADN en las poblaciones estudiadas (rango de edad 18 a 48 años), se puede deber a que el rango de edad no es muy grande, lo cual, no permite ver un efecto importante en los resultados con el ensayo del cometa, de acuerdo con las investigaciones realizadas por Valverde et al. (1997) y Villarini et al. (2002), quienes no hallaron un efecto significativo de la edad sobre los resultados de la prueba de genotoxicidad. Frente al tiempo de exposición de los agricultores y floricultores, no se observó un cambio en los resultados del cometa, pues se debe tener en cuenta que la mayoría de los linfocitos en sangre periférica tienen una vida media menor a dos semanas; así pues nuevos linfocitos son producidos continuamente (Weisenburger E Harrington, 1990). El hecho que la mayoría de los linfocitos tengan una vida media tan baja, no permite ver un efecto acumulativo (a través del tiempo) del daño en el ADN sobre estas células.

\section{CONCLUSIONES Y RECOMENDACIONES}

El ensayo del cometa es una técnica muy sensible, que permite evaluar el daño sobre el ADN generado por cualquier factor interno o externo, sin discriminación alguna; los resultados presentados indican una posible relación con la exposición ocupacional en los lugares de trabajo. Desde que los trabajadores son frecuentemente expuestos a una mezcla de plaguicidas es difícil atribuir el daño genotóxico a una clase de químico o compuesto en particular. Los compuestos organoclorados usados en el pasado han sido remplazados por organofosforados y carbamatos y más recientemente por piretrinas, que representan las clases de pesticidas más usados hoy en día. La evidencia experimental muestra que un amplio rango de estos compuestos induce efectos genotóxicos en bacterias, así como en sistemas animales. Aunque la significancia del incremento de los efectos genotóxico es difícil predecir de forma individual, los hallazgos positivos en este estudio de biomonitoreo sugiere un riego genotóxico a nivel grupal. La evidencia de un riesgo genotóxico relacionado a la exposición, resulta del intensivo uso de plaguicidas y poco uso de elementos de protección; una relación de dosis-efecto puede ser una hipótesis, lo que revela la necesidad de implementar programas para educar a los agricultores en la reducción del uso de plaguicidas e implementar las medidas de protección. Los resultados negativos son asociados con bajos niveles de exposición, por el uso adecuado de elementos de protección y acatamientos de normas de seguridad para el manejo de sustancias tóxicas y el uso de plaguicidas levemente tóxicos. Tanto el género como la edad no reveló ninguna diferencia en el efecto genotóxico de los pesticidas en las poblaciones expuestas, de igual forma, el daño basal en personas no expuestas a sustancias tóxicas parece ser igual en ambos géneros y entre edades. Así mismo en estas poblaciones de trabajadores, no se encontraron efectos acumulativos ante la exposición, puede ser que el efecto agudo que pueda llegar a generar es rápidamente reparado, por los mecanismos de reparación de ADN y así dar un control eficiente de los daños producidos.

Los resultados no pueden ser extrapolados a los demás cultivos de flores o de papa y de cebolla, pues las condiciones, aunque similares, pueden variar, tanto en plaguicidas utilizados, como las normas e implementos 
de seguridad empleados, a pesar de estas limitaciones, con los resultados de esta investigación se podrán llevar a cabo estudios subsiguientes en la exposición ocupacional a plaguicidas y evaluar otras variables que no fueron tenidas en cuenta. Los hallazgos presentados en este estudio proporcionan, adicionalmente, evidencia para la validación del ensayo del cometa como una prueba aplicable en estudios de bio monitoreo de poblaciones humanas.

\section{AGRADECIMIENTOS}

El autor le agradece a la Doctora Helena Groot y Myriam Gutiérrez por su apoyo y colaboración en la realización del trabajo; a la Universidad de Los Andes, por la ayuda económica otorgada para el desarrollo de este proyecto y al Doctor Meyid Antonio Velos Ruiz y a todo su grupo de investigadores de la Universidad Pedagógica y Tecnológica de Colombia, por la recolección de las muestras, evaluación médica y aplicación de las encuestas. Así mismo al profesor Orlando Martínez, por la ayuda en el análisis estadístico.

\section{BIBLIOGRAFÍA}

ÁLVAREZ-MOYA, C.; SANTERRE-LUCAS, A.; ZÚÑIIGAGONZÁLEZ, G.; TORRES-BUGARÍN, O.; PADILLA-CAMBEROS, E.; FERIA-VELASCO. A. 2001. Evaluation of genotoxic activity of maleic hydrazide, ethyl methane sulfonate, and $\mathrm{N}$-nitroso diethylamine in Tradescantia. Salud Publica Mex. 43:563-569.

ANDERSON, D.; YU, T.W.; PHILLIPS, B.J.; SCHMEZER, P. 1994. The effect of various antioxidants and other modifying agents on oxygen-radicalgenerated DNA damage in human lymphocytes in the COMET assay. Mutat. Res. 307(1):261-271.

ANTONUCCI, G.A.; COLUS, IM. 2000. Chromosomal aberrations analysis in a Brazilian population exposed to pesticides. Teratog. Carcinog. Mutag. 20(2):265-272.

BLAIR, A.; CANTOR, K.P.; ZAHM, S.H. 1998. NonHodgkin's lymphoma and agricultural use of the insecticide lindane. Am. J. Ind. Med. 33:82-87.
BLASIAK, J.; JALOSZYNSKI, P.; TRZECIAK, A.; SZYFTER, K. 1999. In vitro studies on the genotoxicity of the organophosphorus insecticide malathion and its two analogues. Mutat. Res. 445(2):275-283.

CARBONELL, E.; PUIG, M.; XAMENA, N.; CREUS, A.; MARCOS, R. 1990. Sister chromatid exchanges in lymphocytes of agricultural workers exposed to pesticides. Mutagenesis. 5(3):403-405.

CLEMENTS, C.; RALPH, S.; PETRAS, M. 1997. Genotoxicity of selected herbicides in Rana catesbiana tadpoles using alkaline single-cell electrophoresis (comet) assay. Environ. Mol. Mutagen. 29(4):277-288.

COMUNIDAD ANDINA CAN. Decisión 436. 2002. Manual Técnico Andino para el registro y control de pesticidas químicos de uso agrícola. Lima, Perú: CAN, 296 de Junio de 2002.

DAVIES, H.W.; KENNEDY, S.M.; TESCHKE, K.; QUINTANA, P.J. 1998. Cytogenetic analysis of South Asian berry pickers in British Columbia using the micronucleus assay in peripheral lymphocytes. Mutat. Res. 416(1):101-113.

DE ROOS, A.J.; ZAHM, S.H.; CANTOR, K.P.; WEISENBURGER, D.D.; HOLMES, F.F.; BURMEISTER, L.F.; BLAIR, A. 2003. Integrative assessment of multiple pesticides as risk factors for non-Hodgkin's lymphoma among men. Occup. Environ. Med. 60:e11

ELHAJOUJI, A. 2001. Use of the alkaline comet assay for industrial genotoxicity screening. Food Chemical Tox. 39(8):843-858.

FAIRBAIRN, D.; OLIVE, P.L.; O'NEILL, K.L. 1995. The comet assay: a comprehensive review. Mutat. Res. 339(1):37-59.

GARAJ-VRHOVAC, V.; ZELJEZIC, D. 1999. Chromosomal aberrations and frecuency of micronuclei in workers employed in pesticides production. Biologia. 54:707-712.

GARAJ-VRHOVAC, V.; ZELJEZIC, D. 2000. Evaluation of DNA damage in workers occupationally exposed 
to pesticides using single-cell gel electrophoresis (SCGE) assay. Pesticide genotoxicity revealed by comet assay. Mutat. Res. 469(2):279-285.

GARAJ-VRHOVAC, V.; ZELJEZIC, D. 2001. Cytogenetic monitoring of croatian population occupationally exposed to a complex mixture of pesticides. Toxicology. 165(2-3):153-162.

GARAJ-VRHOVAC, V.; ZELJEZIC, D. 2002. Assessment of genome damage in a population of Croatian workers employed in pesticides production by chromosomal aberration analysis, micronucleus assay and comet assay. J. Appl. Tox. 22:248-255.

GÓMEZ, S.; NORIEGA, N.; OSORIO, A.; GALICIA, F.; LING, S.; VILLALOBOS, R. 1992. Sister chromatid exchanges in a rural population of Mexico exposed to pesticides. Mutat. Res. 281:173-179.

GÓMEZ-ARROYO, S.; DÍAZ-SANCHEZ, Y.; MENÉSESPÉREZ, M.A.; VILLALOBOS-PIETRINI, R.; DELEÓNRODRÍGUEZ, J.D. 2000. Cytogenetic biomonitoring in a Mexican floriculture worker group exposed to pesticides. Mutat. Res. 466:117-124.

GROVER, P.; DANADEVI, K.; MAHBOOB, M.; ROZATI, R.; BANU, S.; RAHMAN, M. 2003. Evaluation of genetic damage in workers employed in pesticide production utilizing the Comet assay. Mutagenesis. 18(2):201-205.

IARC International Agency for Research on Cancer Monographs. 1991. Occupational Exposures in Insecticide Application and Some Pesticides. 53:45-93.

KASSIE, F.; PARZEFALL, W.; KNASMULLER, S. 2000. Single cell gel electrophoresis assay: a new technique for human biomonitoring studies. Mutat. Res. 463:13-31.

LEBAILLY, P.; VIGREUX, C.; LECHEVREL, C.; LEDEMENEY, D.; GODARD, T.; SICHEL, F.; LETALAER, JY.; HENRY-AMAR, M.; GAUDUCHON, P. 1998. DNA damage in mononuclear leukocytes of farmers measured using the alkaline comet assay: modifications of DNA damage levels after a one-day field spraying period with selected pesticides. Cancer Epidemiol Biomarkers Prev. 7(10):929-940.

LUCERO, L.; PASTOR, S.; SUÁREZ, S.; DURBAN, R.; GÓMEZ, C.; PARRON, T.; CREUS, A.; MARCOS, R. 2000. Cytogenetic biomonitoring of Spanish greenhouse workers exposed to pesticides: micronuclei analysis in peripheral blood lymphocytes and buccal epithelial cells. Mutat. Res. 464:255-262.

MCKELVEY, M.; VALERIE, J. 1998. Emerging applications of the single cell gel electrophoresis (Comet) assay. Mutagenesis. 13(1):1-8.

MERHI, M.; RAYNAL, H.; CAHUZAC, E.; VINSON, F.; CRAVEDI, J.P.; GAMET-PAYRASTRE, L. 2007. Occupational exposure to pesticides and risk of hematopoietic cancers: meta-analysis of case-control studies. Cancer Causes Control. 18(10):1209-1226.

MESTER, B.; NIETERS, A.; DEEG, E.; ELSNER, G.; BECKER, N.; SEIDLER, A. 2006. Occupation and malignant lymphoma: a population based case control study in Germany. Occup. Environ. Med. 63:17-26.

MINISTERIO DE SALUD. Decreto 1843 del 22 de julio de 1991. Disposiciones sanitarias sobre uso y manejo de plaguicidas. Bogotá: Ministerio de Salud; 1991. p.1-69.

MOLLER, P.; KNUDSEN, L.E.; LOFT, S.; WALLIN, H. 2000. The comet assay as a rapid test in biomonitoring occupational exposure to DNAagents and effect of confounding factors. Cancer Epidemiol. Biomarkers Prev. 9(10):1005-1015.

MORETTI, M.; MARCARELLI, M.; VILLARINI, M.; FATIGONI, C.; SCASSELLATI-SFORZOLINI, G.; PASQUINI, R. 2002. In vitro testing for genotoxicity of the herbicide terbutryn: cytogenetic and primary DNA damage. Toxicol In Vitro. 16:81-88.

OLIVE, P.L.; CHAN, A.P.; CU, C.S. 1988. Comparison between the DNA precipitation and alkali unwinding assays for detecting DNA strand breaks and crosslinks. Cancer Res. 48:6444-6449. 
ORSI, L.; TROUSSARD, X.; MONNEREAU, A.; BERTHOU, C.; FENAUX, P.; MARIT, G.; SOUBEYRAN, P.; HUGUET, F.; MILPIED, N.; LEPORRIER, M.; HEMON, D.; CLAVEL, J. 2007. Occupation and lymphoid malignancies: results from a French case-control study. J. Occup. Environ. Med. 49(12):1339-50.

OSTLING, O.;JOHANSON, K.L. 1984. Microelectrophoretic study of radiation-induced DNA damages in individual mamalian cells. Biochem. Biophys. Res. Commun. 123:291-298.

PASTOR, S.; GUTIÉRREZ, S.; CREUS, A.; CEBULSKAWASILEWSKA, A.; MARCOS, R. 2001a. Micronuclei in peripheral blood lymphocytes and buccal epithelial cells of Polish farmers exposed to pesticides. Mutat. Res. 495:147-156.

PASTOR, S.; GUTIÉRREZ, S.; CREUS, A.; XAMENA, N.; PIPERAKIS, S.; MARCOS, R. 2001b. Cytogenetic analysis of Greek farmers using the micronucleus assay in peripheral lymphocytes and buccal cells. Mutagenesis. 16:539-545.

RAHMAN, M.F.; MAHBOOB, M.; DANADEVI, K.; BANU, B.S.; GROVER, P. 2002. Assessment of genotoxic effects of chloropyriphos and acephate by the comet assay in mice leucocytes. Mutat. Res. 516(1):139-147.

ROJAS, E.; LÓPEZ, M.C.; VALVERDE, M. 1999. Single cell gel electrophoresis assay: methodology and applications. J. Chromatography. 722:225-254.

SHAH, R.G.; LAGUEUX, J.; KAPUR, S.; LEVALLOIS, P.; AYOTTE, P.; TREMBLAY, M. 1997. Determination of genotoxicity of the metabolites of pesticides guthion, sencor, lorox, reglone, daconil and admire by P32-postlabeling. Mol. Cell. Biochem. 169:177-184.

SINGH, N.P.; COY, M.I.; TICE, R.; SCHNEIDER, E.L. 1988. A simple technique for quantification of low levels of DNA damage in individual cells. Exp. Cell Res. 175:184-191.

TICE, R.R. 2000. Single Cell Gel/Comet Assay: Guidelines for In Vitro and In Vivo aspects of Genetic Toxicology. Environ. Mol. Mutagen. 35:206-221.
TISCH, M.; SCHMEZER, P.; FAULDE, M.; GROH, A.; MAIER, H. 2002. Genotoxicity studies on permethrin, DEET and diazinon in primary human nasal mucosal cells. Eur. Arch. Otorhinolaryngol. 259(3):150-153.

VALVERDE, M.; LÓPEZ, A.D.L.; LÓPEZ, I.; SÁNCHEZ, I.; FORTOUL, T.I.; OSTROSKY-REPETTO, R.; BALIGA, S.S. 1997. DNA damage in leukocytes and buccal and nasal epithelial cells of individuals exposed to air pollution in Mexico City. Environ. Mol. Mutagen. 30(2):147-152.

VARONA, M.; CÁRDENAS, O.; CRANE, C.; ROCHA, S.; CUERVO, G.; VARGAS, J. 2003. Cytogenetic alterations in field workers routinely exposed to pesticides in Bogotá flowers farms. Biomédica. 23(2):141-152.

VARONA, M.; TOLOSA, J.; CÁRDENAS, O.; TORRES, C.; PARDI, D.; CARRASQUILLA, G.; FRUMKIN, H. 2005. Descripción del uso y manejo de plaguicidas en las empresas de flores afiliadas a Asocolflores. Biomédica. 25:377-389

VIEL, J.F.; CHALLIER, B.; PITARD, A.; POBEL, D. 1998. Brain cancer mortality among French farmers: the vineyard pesticide hypothesis. Arch. Environ. Health. 53:65-70.

VILLARINI, M.; SCASSELLATI-SFORZOLINI, G.; MORETTI, M.; PASQUINI, R. 2002. In vitro genotoxicity of terbutryn evaluated by the alkaline single-cell microgel-electrophoresis "comet" assay. Cell Biol. Toxicol. 16(5):285-292.

WEISENBURGER, D.S.; HARRINGTON, J.O. 1990. Armitage, B-cell neoplasia: a conceptual understanding based on the normal humoral immune response. Pathol. Annu. 25:99-115.

ZELJEZIC, D.; GARAJ-VRHOVAC, V. 2001. Chromosomal aberration and single cell gel electrophoresis (Comet) assay in the longitudinal risk assessment of occupational exposure to pesticides. Mutagenesis. 16(4):359-363.

Recibido: Junio 10 de 2008

Aceptado: Febrero 18 de 2009 